\title{
Lynch syndrome-associated breast cancers do not overexpress chromosome 11-encoded mucins
}

Michael D Walsh ${ }^{1,2}$, Margaret C Cummings ${ }^{3}$, Sally-Ann Pearson ${ }^{1}$, Mark Clendenning ${ }^{1}$, Rhiannon J Walters ${ }^{1}$, Belinda Nagler ${ }^{1}$, John L Hopper ${ }^{4}$, Mark A Jenkins ${ }^{4}$, Graeme K Suthers ${ }^{5,6}$, Jack Goldblatt ${ }^{7,8}$, Kathy Tucker ${ }^{9}$, Michael R Gattas ${ }^{10}$, Julie L Arnold ${ }^{11}$, Susan Parry ${ }^{11}$, Finlay A Macrae ${ }^{12}$, Michael A McGuckin ${ }^{13}$, Joanne P Young ${ }^{1}$ and Daniel D Buchanan ${ }^{1}$

${ }^{1}$ Cancer and Population Studies Group, Queensland Institute of Medical Research, Herston, QLD, Australia; ${ }^{2}$ University of Queensland School of Medicine, Herston, QLD, Australia; ${ }^{3}$ University of Queensland Centre for Clinical Research, Herston, QLD, Australia; ${ }^{4}$ Centre for MEGA Epidemiology, School of Population Health, University of Melbourne, Melbourne, VIC, Australia; ${ }^{5}$ South Australian Clinical Genetics Service, North Adelaide, SA, Australia; ${ }^{6}$ Department of Paediatrics, University of Adelaide, Adelaide, SA, Australia; ${ }^{7}$ Genetic Services of Western Australia, King Edward Memorial Hospital, Subiaco, WA, Australia; ${ }^{8}$ School of Paediatrics and Child Health University of Western Australia, Nedlands, WA, Australia; ${ }^{9}$ Clinical Genetics Service, Prince of Wales Hospital, Randwick, NSW, Australia; ${ }^{10}$ Genetic Health Queensland, Royal Brisbane and Women's Hospital, Herston, QLD, Australia; ${ }^{11}$ New Zealand Familial Gastrointestinal Cancer Registry, Auckland City Hospital, Auckland, New Zealand; ${ }^{12}$ Department of Colorectal Medicine and Genetics, Royal Melbourne Hospital, Parkville, VIC, Australia and ${ }^{13}$ Mater Medical Research Institute, South Brisbane, QLD, Australia

\begin{abstract}
Mismatch repair-deficient breast cancers may be identified in Lynch syndrome mutation carriers, and have clinicopathological features in common with mismatch repair-deficient colorectal and endometrial cancers such as tumour-infiltrating lymphocytes and poor differentiation. Mismatch repair-deficient colorectal cancers frequently show mucinous differentiation associated with upregulation of chromosome 11 mucins. The aim of this study was to compare the protein expression of these mucins in mismatch repair-deficient and -proficient breast cancers. Cases of breast cancer $(n=100)$ were identified from families where (1) both breast and colon cancer co-occurred and (2) families met either modified Amsterdam criteria or had at least one early-onset ( $<50$ years) colorectal cancer. Tumour sections were stained for the epithelial mucins, MUC2, MUC5AC, MUC5B and MUC6, and the homeobox protein CDX2, a regulator of MUC2 expression. In all, 16 mismatch repair-deficient Lynch syndrome breast cancers and $\mathbf{8 4}$ non-Lynch breast cancers were assessed for altered mucin expression. No significant difference in the expression of MUC2, MUC5AC or MUC6 was observed between the mismatch repair-deficient and mismatch repair-proficient breast cancers; however, there was a trend for mismatch repairdeficient tumours to express high levels of MUC5B less frequently $(P=0.07,0 R=0.2(0.0-1.0))$. Co-expression of two or more gel-forming mucins was common. Ectopic expression of CDX2 was associated with expression of MUC2 $(P=0.035, \mathrm{OR}=8.7(1.3-58.4))$. Mismatch repair-deficient breast cancers do not show differential expression of the mucins genes on chromosome 11 when compared with mismatch repair-proficient breast cancers, in contrast with mismatch repair-deficient colorectal and endometrial cancers, which frequently have increased mucin protein expression when compared with their mismatch repair-proficient counterparts. In addition, ectopic CDX2 expression is positively associated with de novo MUC2 expression.
\end{abstract}

Modern Pathology (2013) 26, 944-954; doi:10.1038/modpathol.2012.232; published online 1 February 2013

Keywords: breast cancer; Lynch syndrome; microsatellite instability; mismatch repair; mucin

Correspondence: Dr MD Walsh, PhD, Cancer and Population Studies Group, Queensland Institute of Medical Research, 300 Herston Road, Herston, QLD 4006, Australia.

Email: Michael.Walsh@qimr.edu.au

Received 20 May 2012; revised 30 November 2012; accepted 3 December 2012; published online 1 February 2013
Lynch syndrome is an inherited disorder attributable to germline defects in the DNA-mismatch repair genes, with mutations occurring predominantly in the MLH1 and MSH2 genes, with the majority of the remaining Lynch syndrome cases occurring from 
mutations in MSH6 gene and, to a lesser extent, PMS 2. ${ }^{1}$ The syndrome is characterised by increased susceptibility to cancers of the colorectum, endometrium, small intestine, upper urinary tract, pancreas, biliary tract and brain, and, in patients with the Muir Torre phenotype, also sebaceous skin tumours. ${ }^{2,3}$ Several previous studies have reported an elevated risk of breast cancer in mutationpositive families, ${ }^{4-6}$ whereas other studies have found little to no increase in breast cancer incidence. ${ }^{7,8}$

Following on from reports of mismatch repairdeficient or microsatellite unstable breast cancers (all limited in the number of cases reported), ${ }^{9-16}$ we have recently shown that approximately $50 \%$ of breast cancers arising in mismatch repair genemutation carriers show evidence of mismatch repair deficiency, and that these breast cancers have histopathological features such as poor tumour differentiation and the presence of tumourinfiltrating lymphocytes. ${ }^{17}$ These histopathological features are also commonly seen in colorectal and endometrial cancers with microsatellite instability. ${ }^{18-21}$ Another striking feature of mismatch repair-deficient colorectal and endometrial cancers is an increased incidence of mucinous differentiation. ${ }^{18,19,22}$

The mucin genes on chromosome 11p15.5, MUC2, MUC5AC, MUC5B and MUC6 encode the viscoelastic secreted mucous gels produced by many epithelia, including the gastrointestinal, respiratory and reproductive tracts. Overexpression of MUC2 and MUC5AC is a hallmark of mucinous colorectal carcinomas, ${ }^{23,24}$ and is associated with the presence of microsatellite instability. ${ }^{25}$ Overexpression of MUC2 and MUC5AC is common in colorectal carcinomas with microsatellite instability even where classical mucinous differentiation is lacking (Walsh et al., unpublished data).

The aim of this study was to investigate the expression of the mucin genes that cluster together on chromosome $11 \mathrm{p} 15.5$ in a cohort of breast cancers that have been previously characterised for evidence of mismatch repair deficiency and Lynch syndrome. Mucin expression will be examined in the context of mismatch repair status, breast tumour clinicopathological features and expression of the homeobox protein CDX2.

\section{Patients and methods}

This study extends a previous report of the characterisation of a series of cases of breast cancer identified from the Colorectal Cancer Family Registry (Colon CFR) for evidence of mismatch repair deficiency and Lynch syndrome. ${ }^{17}$ The Colon CFR is a National Cancer Institutesupported consortium established in 1997 to create a comprehensive collaborative infrastructure for interdisciplinary studies of the genetic and molecular epidemiology of colorectal cancer (see detailed information about the registry at the CFR website, http://epi.grants.cancer.gov/ CFR). ${ }^{26}$ All patients in this study had institutional review board approval under the policies and procedures of the Colon CFR for recruitment of participants and protocols for carrying out research projects.

Individuals with breast cancer were selected from families: (1) where both breast and colon cancer cooccurred, with at least one breast cancer regardless of age at diagnosis, (2) that met either modified Amsterdam criteria or had at least one early-onset $(<50$ years) colorectal cancer and (3) where breast tissue was available for testing. For the present study, comprehensive cancer histories and tissue were available for 100 cases of breast cancer arising in 97 individuals from 86 families recruited through the Australasian Colorectal Family Registry. Three individuals had metachronous breast cancers. Three of the patients in the present study were male. An additional four cases of breast cancer arising in germline $\mathrm{MSH} 2$ mutation carriers were included, which did not comprise part of the original patient cohort previously reported. ${ }^{17}$ The specific mutation, personal cancer and family history details are provided in Supplementary Table 1.

All cases of breast cancer were reviewed by one specialist histopathologist (MCC) to confirm diagnosis and score histopathological features. Note was made of the following features: tumour location, size, primary histological type, tumour grade (using the Nottingham modification of Bloom Richardson system ${ }^{27}$ ), the presence of mucinous differentiation, tumour margin, confluent necrosis, calcification, presence of tumour-infiltrating and peritumoural lymphocytes, presence of in situ carcinoma and atypical ductal hyperplasia, and axillary lymph node status. Steroid hormone receptor status was recorded from the original clinical histopathology reports, and, owing to the large number of incomplete reports, where possible these markers were reassessed immunohistochemically in our laboratory. ${ }^{17}$

Germline mutation testing for MSH2 (for the additional cases detailed in Supplementary Table 1), microsatellite instability testing, and immunohistochemistry for the four DNA-mismatch repair proteins and for oestrogen receptor (ER) and progesterone receptor (PR) were performed as previously described. ${ }^{17,20}$ Immunohistochemistry for CDX2 and the MUC2, MUC5AC, MUC5B and MUC6 proteins was performed as follows. Paraffin sections $(4 \mu \mathrm{m})$ were routinely dewaxed and rehydrated, then subjected to heat-induced epitope retrieval in either High pH Target Retrieval solution (Dako, Carpinteria, CA, USA) (MUC2 and MUC6) or Reveal Decloaking solution (BioCare Medical, Concord, MA, USA) for $8 \mathrm{~min}$ and then incubated with primary antibody for $90 \mathrm{~min}$. The antibodies used for this study were (a) anti-MUC2 (clone Ccp58, 1/500 dilution) (Santa Cruz Biotechnology, Santa Cruz, CA, USA), (b) anti-MUC5AC (clone 45M1, 1/750 dilution) (Neomarkers, Fremont, CA, USA), (c) anti-MUC6 (clone CLH5, 1/250 dilution) (Santa Cruz Biotechnology), (d) anti-MUC5B (clone EU-MUC5B, 1/500 dilutionkindly supplied by Dr Karine Rousseau, Manchester, UK) and (e) anti-CDX2 (clone CDX2-88, 1/100 dilution) (BioCare Medical), followed by the EnVision Plus Mouse 
HRP detection system (Dako). Antigenic sites were developed using DAB + liquid chromogen (Dako), and then the sections were counterstained with haematoxylin before mounting.

Statistical analysis was carried out using Statistical Package for Social Sciences (SPSS, version 17.0). Contingency tables were assessed using $\chi^{2}$ - or Fisher's exact test as appropriate. Differences between means were assessed using a $t$-test after testing to ensure equality of the variance in groups using probability plots and an F-test. $P$-values $<0.05$ were considered significant.

\section{Results}

The cohort of patients comprised 94 females and 3 males with an average age of $56.0 \pm 10.8$ years (average age \pm s.d), ranging from 36.1 to 80.5 years. Of these, 16 individuals showed immunohistochemical evidence of mismatch repair deficiency, with 4 cases showing loss of expression of MLH1 and PMS2, 11 cases showing loss of expression of MSH2 and MSH6 and 1 case demonstrating loss of MSH6 expression only. In each of these 16 cases, the loss of expression of the DNA-mismatch repair protein corresponded to the gene harbouring the pathogenic germline mutation. There was no statistically significant difference in mean ages between the mismatch repair-proficient and -deficient groups ( $55.8 \pm 11.4$ vs $57.0 \pm 6.7$ years, respectively). Of the 100 tumours examined, 10 were ductal carcinoma in situ-only, and the remaining cohort of invasive carcinomas comprised 65 infiltrating ductal carcinomas NOS, 2 medullary cancers, 2 tubular carcinomas, 18 infiltrating lobular carcinomas, 1 ductal carcinoma with neuroendocrine differentiation and two mixed carcinomas; 1 ductal and mucinous carcinoma and 1 ductal and cribriform carcinoma. Axillary lymph node status was available for 72 cases, and of these, $24(33 \%)$ cases had nodal involvement by tumour. Of the tumours for which ER and PR status were available, 54/83 (65\%) and 54/81 (67\%) were ER- and PR-positive respectively.

\section{MUC2}

MUC2 expression was observed in 17/100 (17\%) cases of breast carcinoma and was characterised by intense cytoplasmic staining. In the majority of cases $(14 / 17 ; 82 \%)$, less than $10 \%$ of tumour cells were immunoreactive (Figure 1a). Of the 90 cases of invasive breast cancer, 51 had co-existing in situ carcinoma, and of these, 7 (14\%) were MUC2 positive, and expression levels within the in situ and invasive components were comparable (Figure 1b). Both cases that showed foci of mucinous differentiation showed MUC2 reactivity (Figure 1c). A single case of infiltrating lobular carcinoma also showed extensive reactivity for MUC2 (Figure 1d). Normal and benign ductal and acinar epithelial cells were consistently MUC2 negative. MUC2 immunoreactivity within tumours was not associated with mismatch repair status, nor with tumour clinicopathological features or with steroid hormone receptor expression status. There was, however, a positive association between ectopic CDX2 expression and MUC2 positivity $(P=0.035, \quad O R=8.7$ (1.3-58.4)) (Table 1) (Figure 3d).

\section{MUC5AC}

Sixteen cases of breast cancer were found to express MUC5AC (16/95; 17\%) where reactivity was cytoplasmic. Extracellular material within gland spaces was also commonly positive in these cases (Figure 1e). As was the case for MUC2, staining in the majority of MUC5AC-positive cases was restricted to $<10 \%$ of tumour cells (13/17; 76\%). Five of the positive cases were DCIS without an invasive component, and of the remaining 12 cases of invasive malignancy, 7 had co-existing DCIS in which MUC5AC expression mirrored the invasive component in terms of both the proportion of cells stained and staining intensity. MUC5AC reactivity was present in one case with mucinous differentiation, and, interestingly, was strongly positive in a case of medullary carcinoma (Figure 1f). MUC5AC expression was noted in occasional normal breast ducts as strong staining of luminal contents with weak cytoplasmic reactivity in duct epithelium. The presence of lymphovascular invasion was found to be associated with MUC5AC expression $(P=0.047$, $\mathrm{OR}=4.7$ (1.1-20.3); Table 1). No additional associations between MUC5AC expression and mismatch repair status, histopathological features or ER or PR expression were observed (Table 1).

\section{MUC5B}

Unlike the other 11p15.5 mucins, MUC5B was commonly expressed in both invasive and in situ breast cancers. Expression within normal breast ducts was common, with weak-to-moderate cytoplasmic reactivity in epithelial cells, as well as intense staining of luminal contents. Only 4/80 cases $(5 \%)$ showed no evidence of MUC5B immunoreactivity, but retained staining of normal breast ducts. Within both invasive and in situ-only cancers, staining showed considerable intra- and intertumoral heterogeneity in terms of both the proportion of tumour cells stained and average staining intensity (Figures 2c-e). In order to determine whether the extent of MUC5B expression was related to tumour characteristics, cases were classified as either MUC5B LOW/NEG or MUC5B-HIGH by multiplying the proportion code and average intensity code to give a score range of $0-15$, with a threshold of 8 (representing at least $50 \%$ of tumour cells (proportion score 4), showing at least moderate staining intensity (intensity score 2)) classified as 

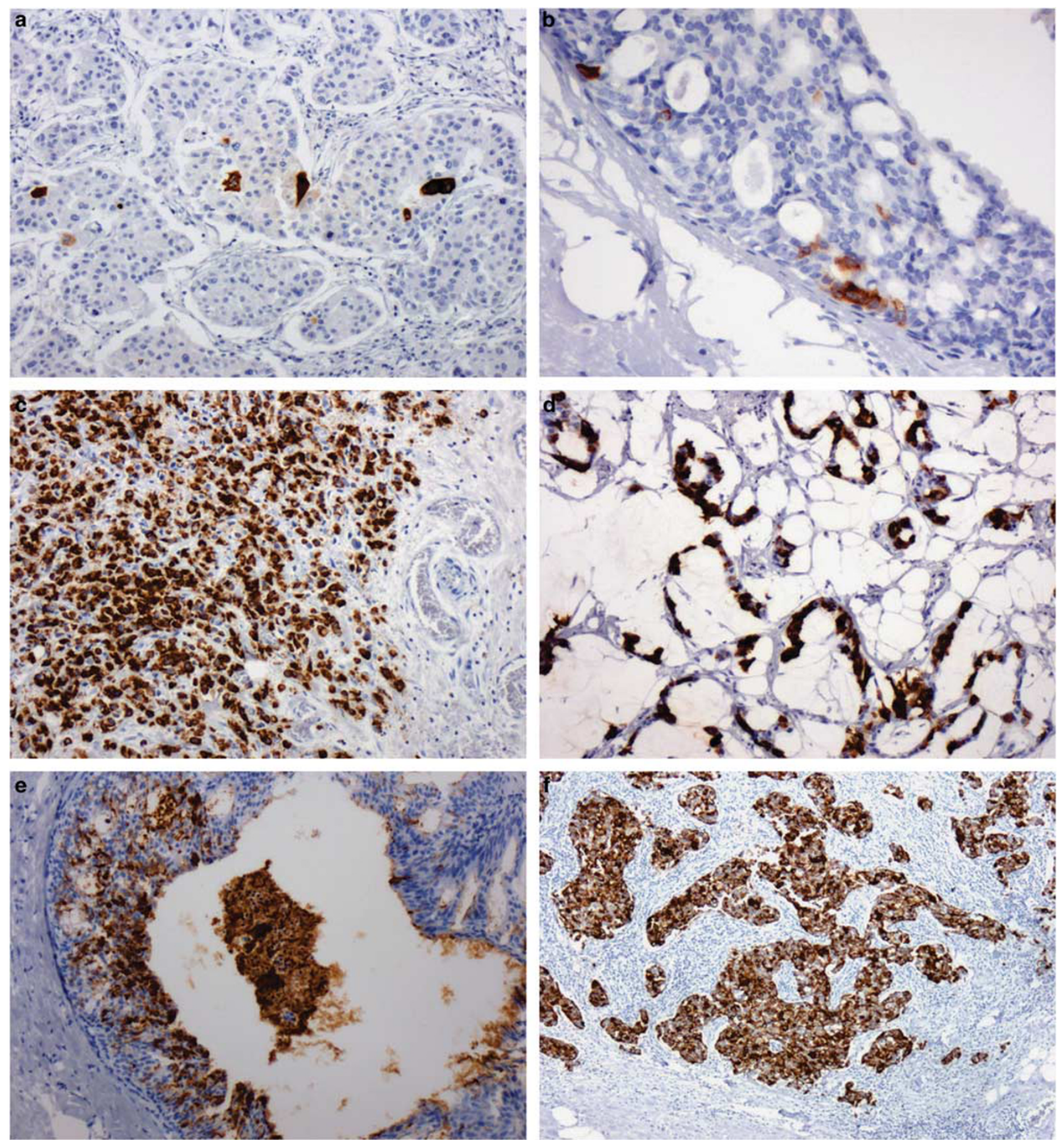

Figure 1 (a) Low proportion of MUC2-positive cells in an invasive ductal carcinoma. (b) Low proportion of MUC2-positive cells in ductal carcinoma in situ from the same case as a. (c) Diffuse strong expression of MUC2 in an infiltrating lobular carcinoma. (d) Strong MUC2 expression in a focus of mucinous differentiation in an IDC. (e) MUC5AC expression in DCIS. (f) Diffuse strong MUC5AC expression in a medullary carcinoma.

MUC5B-HIGH. Using this classification system, a trend between mismatch repair deficiency and fewer cases expressing high levels of MUC5B was found $(P=0.07, \quad$ OR $=0.2 \quad(0.0-1.0))$; however, MUC5B expression was not related to any other clinicopathological or molecular tumour features (Table 2). Apocrine metaplasia was present in three cases examined, and in each instance, there was moderately intense cytoplasmic staining of epithelial cells (Figure 2f).

\section{MUC6}

Normal breast ducts were positive for MUC6 to varying degrees in all cases where present in the 
Table 1 MUC2 and MUC5AC expression related to tumour molecular and clinicopathological features

\begin{tabular}{|c|c|c|c|c|c|}
\hline Feature & & $\begin{array}{c}\text { MUC2 } \\
\text { positive }\end{array}$ & $\begin{array}{c}\mathrm{P} \\
\text { OR }(95 \% \text { CI })\end{array}$ & $\begin{array}{c}\text { MUC5AC } \\
\text { positive }\end{array}$ & $\begin{array}{c}\mathrm{P} \\
\text { OR }(95 \% \text { CI })\end{array}$ \\
\hline \multirow[t]{2}{*}{ Mismatch repair status } & Proficient & $14 / 84(17 \%)$ & 1.00 & $14 / 79(18 \%)$ & 1.00 \\
\hline & Deficient & $3 / 16(19 \%)$ & $1.25(0.0-4.6)$ & $2 / 16(13 \%)$ & $0.7(0.1-3.3)$ \\
\hline \multirow{4}{*}{ Tumour histotype } & IDC & $10 / 66(15 \%)$ & $0.50 *$ & $9 / 62(15 \%)$ & $0.29^{*}$ \\
\hline & ILC & $2 / 18(11 \%)$ & $0.7(0.1-3.5)$ & $1 / 18(6 \%)$ & $0.3(0.0-2.9)$ \\
\hline & Mucinous/IDC & $1 / 1(100 \%)$ & & $1 / 1(100 \%)$ & \\
\hline & Other & $1 / 5(20 \%)$ & & $1 / 4(25 \%)$ & \\
\hline \multirow[t]{3}{*}{ Tumour size } & $<11 \mathrm{~mm}$ & $2 / 20(10 \%)$ & 0.49 & $1 / 18(6 \%)$ & 0.12 \\
\hline & $11-20 \mathrm{~mm}$ & $7 / 34(21 \%)$ & & $8 / 33(24 \%)$ & \\
\hline & $>20 \mathrm{~mm}$ & $4 / 33(12 \%)$ & & $3 / 31(10 \%)$ & \\
\hline \multirow[t]{3}{*}{ Grade } & 1 & $1 / 19(5 \%)$ & 0.37 & $3 / 17(18 \%)$ & 0.79 \\
\hline & 2 & $8 / 42(19 \%)$ & & $6 / 40(15 \%)$ & \\
\hline & 3 & $5 / 29(17 \%)$ & & $3 / 31(11 \%)$ & \\
\hline \multirow{2}{*}{ Lymph node metastases } & Absent & $8 / 48(17 \%)$ & 0.74 & $6 / 46(13 \%)$ & 0.32 \\
\hline & Present & $3 / 24(13 \%)$ & $0.7(0.02-3.0)$ & $5 / 22(23 \%)$ & $2.0(0.5-7.3)$ \\
\hline \multirow[t]{2}{*}{ Lymphovascular invasion } & Absent & $10 / 68(15 \%)$ & 0.43 & $7 / 65(11 \%)$ & 0.047 \\
\hline & Present & $3 / 10(23 \%)$ & $1.7(0.4-7.5)$ & $4 / 11(36 \%)$ & $4.7(1.1-20.3)$ \\
\hline \multirow{2}{*}{ PTL } & Absent & $10 / 66(15 \%)$ & 0.55 & $10 / 62(16 \%)$ & 1.00 \\
\hline & Present & $6 / 28(21 \%)$ & $1.5(0.5-4.7)$ & $4 / 27(15 \%)$ & $1.9(0.6-6.2)$ \\
\hline \multirow[t]{2}{*}{ TIL } & Absent & $11 / 66(17 \%)$ & 1.00 & $5 / 62(13 \%)$ & 0.34 \\
\hline & Present & $5 / 28(189 \%)$ & $1.1(0.3-3.5)$ & $6 / 27(22 \%)$ & $1.9(1.6-6.2)$ \\
\hline \multirow[t]{2}{*}{ ER status } & Positive & $9 / 54(17 \%)$ & 0.76 & $10 / 53(19 \%)$ & 0.76 \\
\hline & Negative & $6 / 29(21 \%)$ & $1.3(0.4-4.1)$ & $4 / 29(14 \%)$ & $0.7(0.2-2.4)$ \\
\hline \multirow{2}{*}{ PR status } & Positive & $11 / 54(20 \%)$ & 0.37 & $11 / 53(21 \%)$ & 0.20 \\
\hline & Negative & $3 / 27(11 \%)$ & $0.5(0.1-1.9)$ & $2 / 27(7 \%)$ & $0.3(0.1-1.5)$ \\
\hline \multirow[t]{2}{*}{ CDX2 expression } & Negative & $11 / 75(15 \%)$ & 0.04 & $12 / 75(16 \%)$ & 0.52 \\
\hline & Positive & $3 / 5(60 \%)$ & $8.7(1.3-58.4)$ & $1 / 4(25 \%)$ & $1.8(0.2-18.3)$ \\
\hline
\end{tabular}

${ }^{*} P$-value and OR calculated for IDC vs ILC.

sections stained (Figure 3a). MUC6 expression was seen in $34 / 82$ cases $(41 \%)$ of breast cancer ( 6 cases of in situ-only disease and 28 cases of invasive cancer). In $9 / 34$ cases $(26 \%)$, expression was characterised by intense cytoplasmic staining of $<10 \%$ tumour cells, with more diffuse, intense reactivity noted in the remainder. Expression of MUC6 in co-existing DCIS was comparable in intensity and proportion of cells stained to the invasive component (Figures 3b and c). There was no statistical association between MUC6 expression and mismatch repair status, tumour clinicopathological or molecular characteristics; however, there was evidence that MUC6 expression was overrepresented in breast cancer cases where the presence of lymph node metastases was noted $(P=0.060, \mathrm{OR}=3.3(1.1-10.4))$.

\section{Co-expression of mucins}

Co-expression of two or more of the 11p15.5encoded mucins was observed for several breast tumours (shown schematically together with mismatch repair status in Figure 4). Of the 16 MUC2positive tumours, 7 (44\%) co-expressed MUC5AC, whereas only $9 / 79 \quad(11 \%) \quad$ MUC2-negative cancers stained for MUC5AC $(P=0.005$, OR $=6.1$ (1.8-20.2)). Similarly, 10/15 (67\%) MUC2-positive cancers also expressed MUC6, whereas only 24/67 (35.8\%) MUC2-negative cases was MUC6 positive $(P=0.042, \quad$ OR $=3.6 \quad(1.1-11.7)) . \quad$ MUC5AC and
MUC5B-HIGH co-expression was seen in 9/13 cases (69\%) compared with just 4/50 (8\%) MUC5B LOW/ NEG tumours $(P=0.012$, OR $=5.2(1.4-18.8))$. MUC5AC and MUC5B-HIGH expression were unrelated to the presence of MUC6 positivity $(P=0.770$, $\mathrm{OR}=1.2 \quad(0.4-3.9) \quad$ and $\quad P=0.485, \quad \mathrm{OR}=1 . \quad 5$ (0.6-3.6), respectively). There was no statistical difference in the age of onset of cases expressing one or more mucin proteins compared with negative cases (data not shown).

\section{Discussion}

In the present study, we have examined the expression of the epithelial mucins MUC2, MUC5AC, MUC5B and MUC6, in a series of breast cancers in relation to mismatch repair deficiency and Lynch syndrome, as well as clinicopathological features, ER and PR status and the expression of CDX2. Overall, we found no evidence for an association between altered mucin protein expression in breast cancers with mismatch repair deficiency when compared with mismatch repair-proficient breast cancers. This study represents the first report of expression data for all four 11p15.5 mucin genes on a single substantial series of breast cancer cases.

Mucinous differentiation is a common feature of microsatellite unstable colorectal and endometrial cancers, ${ }^{18,19,22}$ but the results of the current study indicate that microsatellite instability is not a 

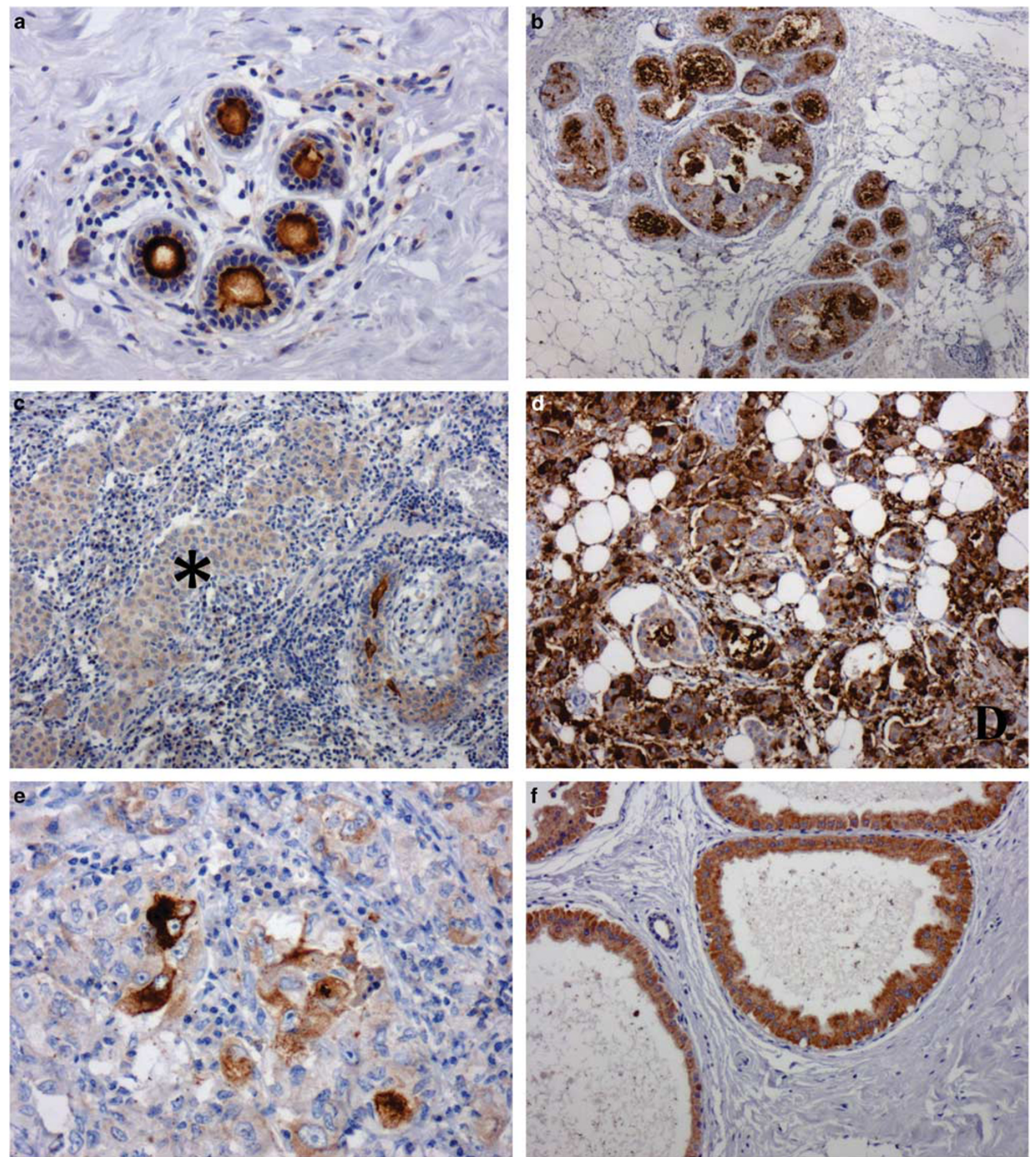

Figure 2 (a) MUC5B expression in normal ducts including luminal contents. (b) Strong MUC5B expression in DCIS. (c) Diffuse but weak MUC5B expression in an infiltrating ductal carcinoma $\left({ }^{*}\right)$ with retention of strong staining in the normal ducts present in the lower right. (d) Diffuse strong staining in an infiltrating carcinoma. (e) Pronounced intra-tumoral heterogeneity of expression of MUC5B in a poorly differentiated ductal carcinoma. (f) MUC5B expression in a focus of apocrine metaplasia.

predisposing factor to chromosome 11 mucin gene overexpression (or mucinous differentiation) in breast cancers from Lynch syndrome patients, which is consistent with evidence that microsatellite instability is rarely found in mucinous breast cancers per se. ${ }^{28}$ Pure mucinous (colloid) breast cancers are relatively uncommon, accounting for approximately $2 \%$ of all invasive epithelial tumours. ${ }^{29}$ In the present study, only one breast cancer showed mucinous differentiation 

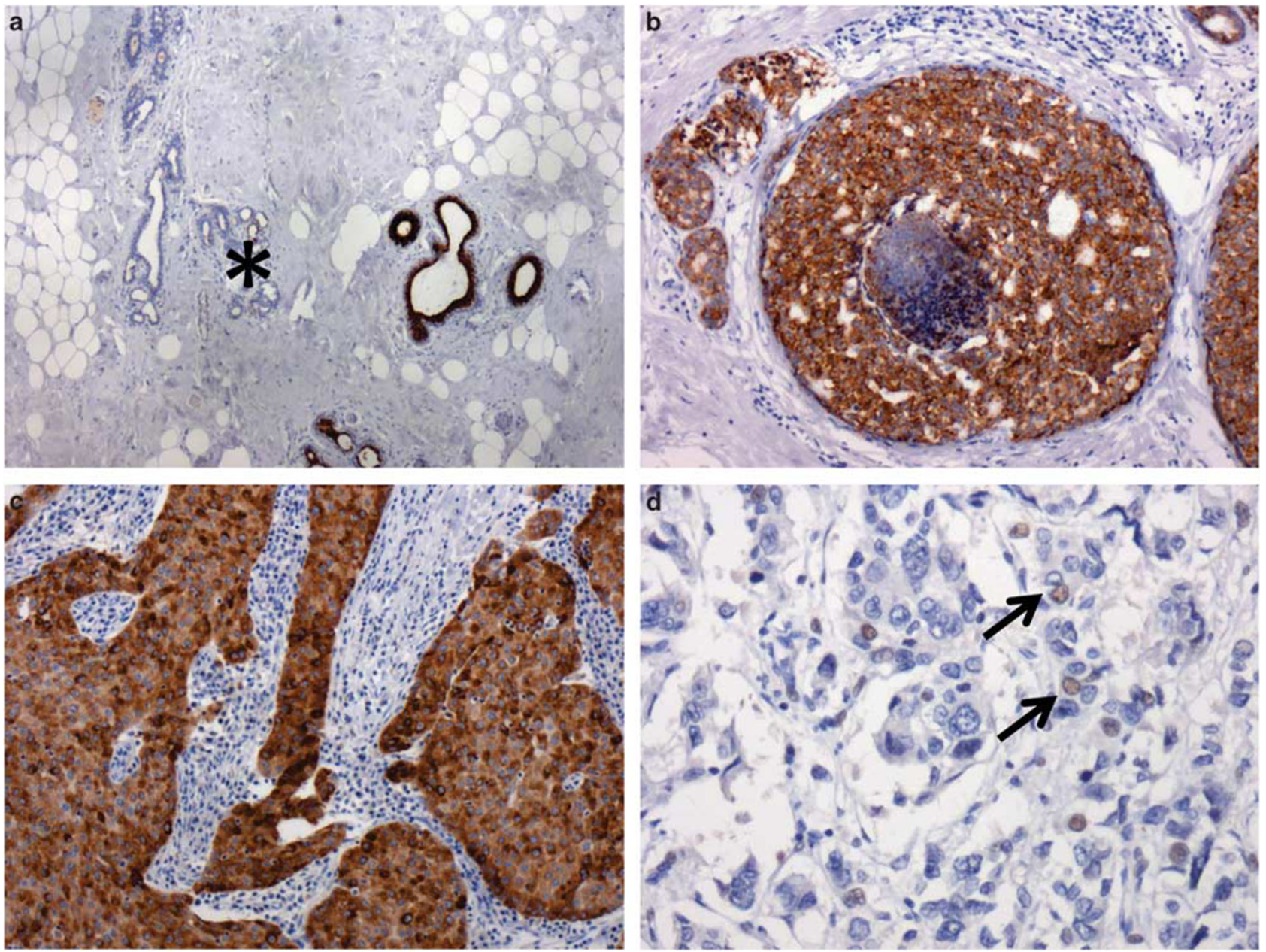

Figure 3 (a) Heterogeneous MUC6 expression showing areas of weak or no expression (*) adjacent to areas that are strongly stained. (b) Strong diffuse MUC6 expression in an area of comedo DCIS. (c) Diffuse MUC6 reactivity in a medullary carcinoma. (d) Ectopic CDX2 expression (arrows) in an IDC that was also MUC2 positive.

(mixed mucinous and ductal adenocarcinoma NOS), and this case demonstrated no evidence of mismatch repair deficiency and was from a patient without a mismatch repair gene mutation (non-Lynch syndrome patient).

Several groups have demonstrated high levels of expression of MUC2 in mucinous breast cancers, ${ }^{30-33}$ and immunoreactivity for MUC6 in these tumours has also been noted. ${ }^{32,34}$ However, there are no systematic studies of expression of the $11 \mathrm{p} 15.5$ mucins in breast cancers. We have previously reported expression of MUC2 in 19\% of breast cancers, ${ }^{35}$ and other studies have reported MUC2 expression in non-mucinous breast cancers ranging between 6 and $38 \%{ }^{33,34,36-38}$ Two published reports have suggested that MUC5AC is rarely expressed in breast cancer. ${ }^{34,36}$ Sóñora et al. ${ }^{39}$ reported MUC5B protein expression in $81 \%$ of cases, whereas $50 \%$ of breast cancers in a separate study demonstrated positive mRNA expression for MUC5B. ${ }^{40}$ The expression of MUC6 has been reported to occur in $13-100 \%$ of breast cancer cases. ${ }^{34,41,42}$ Our finding of considerable heterogeneity of MUC5B expression is in keeping with the previous report by Sóñora et al. ${ }^{39}$ Breast cancers with high MUC5B expression were less likely to be mismatch repair deficient, although this observation was not statistically significant. The mechanisms underpinning mucin expression and acquisition of a mucinous phenotype in microsatellite unstable cancers of the colorectum and endometrium have not been elucidated, and it appears that a similar milieu favouring mucin gene expression does not exist in breast epithelium.

The regulation of mucin genes is complex, multifactorial and only partially understood. Gene promoter silencing by $\mathrm{CpG}$ island methylation, transcriptional regulation through the EGFR-RASRAF and other signalling pathways, and the stimulatory and inhibitory effects of cytokines secreted by peritumoural inflammatory cells, all contribute to a pro- or contra-mucin environment (reviewed by Andrianifahanana et al. ${ }^{43}$ ). The somatic V600E $B R A F$ mutation, commonly associated with sporadic 
Table 2 MUC5B and MUC6 expression related to tumour molecular and clinicopathological features

\begin{tabular}{|c|c|c|c|c|c|}
\hline Feature & & $\begin{array}{l}\text { MUC5B positive } \\
\text { (high expression) }\end{array}$ & $\begin{array}{c}\mathrm{P} \\
O R(95 \% C I)\end{array}$ & MUC6 positive & $\begin{array}{c}\mathrm{P} \\
O R(95 \% \quad C I)\end{array}$ \\
\hline \multirow[t]{2}{*}{ Mismatch repair status } & Proficient & $27 / 65(42 \%)$ & 0.07 & $27 / 67(40 \%)$ & 0.77 \\
\hline & Deficient & $2 / 15(13 \%)$ & $0.2(0.0-1.0)$ & $7 / 15(47 \%)$ & $1.3(0.4-4.0)$ \\
\hline \multirow[t]{4}{*}{ Tumour histotype } & IDC & $17 / 54(32 \%)$ & $0.07 *$ & $22 / 55(40 \%)$ & 0.51 * \\
\hline & ILC & $8 / 14(57 \%)$ & $2.9(0.9-9.7)$ & $5 / 14(36 \%)$ & $0.8(0.2-2.8)$ \\
\hline & Mucinous/IDC & NT & & NT & \\
\hline & Other & $1 / 4(25 \%)$ & & $2 / 4(50 \%)$ & \\
\hline \multirow[t]{3}{*}{ Tumour size } & $<11 \mathrm{~mm}$ & $5 / 15(33 \%)$ & 0.16 & $9 / 15(60 \%)$ & 0.11 \\
\hline & $11-20 \mathrm{~mm}$ & $13 / 26(50 \%)$ & & $11 / 26(42 \%)$ & \\
\hline & $>20 \mathrm{~mm}$ & $7 / 28(25 \%)$ & & $8 / 29(28 \%)$ & \\
\hline \multirow[t]{3}{*}{ Grade } & 1 & $5 / 16(31 \%)$ & 0.77 & $8 / 16(50 \%)$ & 0.53 \\
\hline & 2 & $13 / 32(41 \%)$ & & $11 / 33(33 \%)$ & \\
\hline & 3 & $8 / 24(33 \%)$ & & $9 / 24((38 \%)$ & \\
\hline \multirow[t]{2}{*}{ Lymph node metastases } & Absent & $13 / 37(35 \%)$ & 1.00 & $6 / 23(26 \%)$ & 0.06 \\
\hline & Present & $7 / 22(32 \%)$ & $0.9(0.3-2.7)$ & $20 / 37(54 \%)$ & $3.3(1.1-10.4)$ \\
\hline \multirow{2}{*}{ Lymphovascular invasion } & Absent & $18 / 52(35 \%)$ & 0.51 & $23 / 53(43 \%)$ & 0.50 \\
\hline & Present & $5 / 11(46 \%)$ & $1.6(0.4-5.9)$ & $3 / 11(27 \%)$ & $0.5(0.1-2.1)$ \\
\hline \multirow[t]{2}{*}{ PTL } & Absent & $20 / 52(38 \%)$ & 0.80 & $24 / 54(44 \%)$ & 0.20 \\
\hline & Present & $8 / 23(35 \%)$ & $0.9(0.3-2.4)$ & $6 / 23(26 \%)$ & $0.4(0.2-1.3)$ \\
\hline \multirow[t]{2}{*}{ TIL } & Absent & $18 / 49(37 \%)$ & 1.00 & $21 / 51(41 \%)$ & 0.63 \\
\hline & Present & $10 / 26(39 \%)$ & $1.1(0.4-2.9)$ & $9 / 26(35 \%)$ & $0.8(0.3-2.0)$ \\
\hline \multirow[t]{2}{*}{ ER status } & Positive & $18 / 44(41 \%)$ & 1.00 & $18 / 44(41 \%)$ & 0.80 \\
\hline & Negative & $10 / 25(40 \%)$ & $1.0(0.6-2.6)$ & $12 / 26(46 \%)$ & $1.2(0.5-3.3)$ \\
\hline \multirow[t]{2}{*}{ PR status } & Positive & $19 / 44(43 \%)$ & 0.60 & $19 / 44(43 \%)$ & 1.00 \\
\hline & Negative & $8 / 23(35 \%)$ & $0.7(0.3-2.0)$ & $10 / 24(42 \%)$ & $0.9(0.3-2.6)$ \\
\hline \multirow[t]{2}{*}{ CDX2 expression } & Negative & $28 / 74(38 \%)$ & 0.65 & $30 / 75(40 \%)$ & 0.64 \\
\hline & Positive & $1 / 5(20 \%)$ & $0.4(0.0-3.9)$ & $3 / 5(60 \%)$ & $2.3(0.4-14.3)$ \\
\hline
\end{tabular}

NT, not tested.

${ }^{*} P$-value and OR calculated for IDC vs ILC.

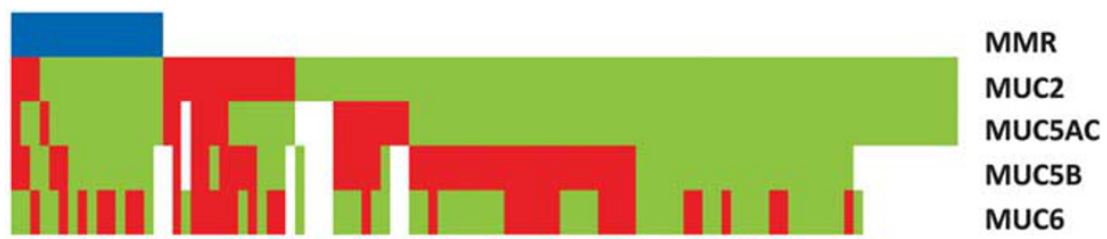

Figure 4 'Heat map' schematic representation of mucin co-expression in breast cancers related to mismatch repair deficiency. The x-axis represents all the 100 breast tumours grouped by mucin expression and mismatch repair status on the y-axis. Mismatch repair-deficient cancers are highlighted on the top line in blue. Positive cases for each immunohistochemical stain are indicated in red, negative in green and blank indicates not stained.

microsatellite unstable colorectal cancers, is rarely, if ever, encountered in breast cancers $^{17}$ but is strongly associated with mucin overexpression in the colon. ${ }^{44}$ Similarly, KRAS and EGFR somatic mutations are uncommon in breast cancers, ${ }^{45-47}$ although EGFR amplification and protein overexpression are frequent occurrences in triplenegative and HER2-positive breast cancers. ${ }^{48}$ More than half of colorectal cancers, on the other hand, have activating mutations in either BRAF or $K R A S, 49,50$ and this may contribute to the differences in mucinous differentiation between the two tumour types.

The homeobox protein CDX2 is a key transcriptional regulator of MUC2 expression in colonic goblet cells. ${ }^{51}$ Aberrant expression of CDX2 has been linked to de novo MUC2 in gastric intestinal metaplasia $^{52}$ and Barrett's oesophagus, ${ }^{53}$ and ectopic low-level CDX2 expression has also been reported in breast cancers by Werling et al. ${ }^{54}$ Five patients in the current study showed low-level de novo CDX2 expression, and, although numbers were few and the confidence intervals wide, this was significantly correlated with MUC2 expression, and is the first time such an association has been demonstrated in the breast. Three of the five individuals in whom low-level CDX2 expression was noted had no personal history of colorectal cancers, and two of the tumours expressed steroid hormone receptors, making it very unlikely that the breast tumours were, in fact, metastatic gastrointestinal malignancies.

The findings from this study demonstrating a lack of association between expression of individual 11p15.5 mucin genes and breast tumour clinicopathological features and steroid hormone receptor 
status are consistent with previous reports. ${ }^{32,39,42,55}$ The observation in this study that MUC5AC expression was nearly five times more common in breast tumours with lymphovascular invasion (an indicator of poor prognosis) warrants further investigation. This is further supported by the report of poor outcome in patients with colorectal cancer that demonstrated overexpression of MUC5AC. ${ }^{56}$

Gaining insight into the expression of $11 \mathrm{p} 15.5$ mucin genes in breast cancer has been hampered by methodological differences in detecting mucin proteins or mRNA. MUC2 expression was found in $17 \%$ of cases in the present study-comparable to previous reports. ${ }^{34,35}$ However, Ho et al. reported either 6 or $38 \%$ positivity in their same case set depending on which anti-MUC2 antibody was used. $^{37}$ Similar differences in expression levels in MUC6 are apparent depending on which anti-MUC6 antibodies were used: de Bolós et al. ${ }^{42}$ reported virtually universal expression of MUC6 by breast cancers using a polyclonal antibody, whereas other studies using monoclonal anti-MUC6 antibodies have yielded expression rates of $13-20 \%, 32,34,36$ and MUC6 mRNA was detected in 3/14 (21\%) of cases of breast cancer studied by Berois et al. ${ }^{40}$ In the present study, all tumours with any evidence of staining for MUC6 were classified as positive $(34 / 82 ; 41 \%)$, but of these, $26 \%$ showed staining in $<10 \%$ of tumour cells. If low-level positive $(<10 \%$ tumour cells stained) cases are excluded, the overall rate of positivity for MUC6 drops to $25 / 82$ cases $(30 \%)$. Rakha et $a .^{32}$ for example, only scored cases with $>5 \%$ MUC6stained cells as positive, and, in their study, 20\% of cases of breast cancer were classified as MUC6 positive. Agreement on thresholds for positivity for scoring immunohistochemistry for many markers remains elusive and may explain the discordance between studies.

In conclusion, we have demonstrated that expression of the 11p15.5 mucin genes in a series of breast cancers was unrelated to mismatch repair status. In contrast to colorectal and endometrial cancers with microsatellite instability, mismatch repair-deficient breast cancers do not have a propensity to express secreted mucins nor do they have a mucinous histological phenotype. The significant observations involving the co-expression of mucins within a breast tumour and the co-expression of MUC2 and CDX2 may help elucidate the biological mechanisms surrounding aberrant mucin expression and highlight important regulatory pathways for these proteins in breast and other tissue types.

\section{Acknowledgements}

This work was supported by the National Cancer Institute, National Institutes of Health under RFA no. CA-95-011 and through the Australasian Colorectal Cancer Family Registry cooperative agreement
(U01 CA097735). The content of this manuscript does not necessarily reflect the views or policies of the National Cancer Institute or any of the collaborating centres in the CFRs, nor does mention of trade names, commercial products or organisations imply endorsement by the US Government or the CFR. Breast tissue samples in this study were obtained from the Jeremy Jass Memorial Tissue Pathology Bank. We are also grateful to the many pathology laboratories involved for supply of extra archived breast tissue for analysis. We thank Judi Maskiell, Leanne Prior, Kelly Aujard, Erika Pavluk and Maggie Angelakos for data and pedigree retrieval, and to members of the families who have given significant time and effort to the contribution of data. During this study, Joanne Young was a Cancer Council Queensland Senior Research Fellow, and Michael McGuckin is supported by an NHMRC Senior Research Fellowship.

\section{Disclosure/conflict of interest}

The authors declare no conflict of interest.

\section{References}

1 Woods MO, Williams P, Careen A, et al. A new variant database for mismatch repair genes associated with Lynch syndrome. Hum Mutat 2007;28:669-673.

2 Vasen HF. Review article: the Lynch syndrome (hereditary nonpolyposis colorectal cancer). Aliment Pharmacol Ther 2007;26(Suppl 2):113-126.

3 Mathiak M, Rutten A, Mangold E, et al. Loss of DNA mismatch repair proteins in skin tumors from patients with Muir-Torre syndrome and MSH2 or MLH1 germline mutations: establishment of immunohistochemical analysis as a screening test. Am J Surg Pathol 2002;26:338-343.

4 Scott RJ, McPhillips M, Meldrum CJ, et al. Hereditary nonpolyposis colorectal cancer in 95 families: differences and similarities between mutation-positive and mutation-negative kindreds. Am J Hum Genet 2001;68:118-127.

5 Oliveira Ferreira F, Napoli Ferreira CC, Rossi BM, et al. Frequency of extra-colonic tumors in hereditary nonpolyposis colorectal cancer (HNPCC) and familial colorectal cancer (FCC) Brazilian families: An analysis by a Brazilian Hereditary Colorectal Cancer Institutional Registry. Fam Cancer 2004;3:41-47.

6 Win AK, Young JP, Lindor NM, et al. Colorectal and other cancer risks for carriers and noncarriers from families with a DNA mismatch repair gene mutation: a prospective cohort study. J Clin Oncol 2012;30: 958-964.

7 Müller A, Edmonston TB, Corao DA, et al. Exclusion of breast cancer as an integral tumor of hereditary nonpolyposis colorectal cancer. Cancer Res 2002;62:1014-1019.

8 Vasen HF, Morreau H, Nortier JW. Is breast cancer part of the tumor spectrum of hereditary nonpolyposis colorectal cancer? Am J Hum Genet 2001;68: 1533-1535. 
9 Shanley S, Fung C, Milliken J, et al. Breast cancer immunohistochemistry can be useful in triage of some HNPCC families. Fam Cancer 2009;8:251-255.

10 Westenend PJ, Schutte R, Hoogmans MM, et al. Breast cancer in an MSH2 gene mutation carrier. Hum Pathol $2005 ; 36: 1322-1326$

11 Bergthorsson JT, Egilsson V, Gudmundsson J, et al. Identification of a breast tumor with microsatellite instability in a potential carrier of the hereditary nonpolyposis colon cancer trait. Clin Genet 1995;47: 305-310.

12 Boyd J, Rhei E, Federici MG, et al. Male breast cancer in the hereditary nonpolyposis colorectal cancer syndrome. Breast Cancer Res Treat 1999;53:87-91.

13 Caluseriu O, Cordisco EL, Viel A, et al. Four novel MSH2 and MLH1 frameshift mutations and occurrence of a breast cancer phenocopy in hereditary nonpolyposis colorectal cancer. Hum Mutat 2001;17:521-525.

14 Risinger JI, Barrett JC, Watson P, et al. Molecular genetic evidence of the occurrence of breast cancer as an integral tumor in patients with the hereditary nonpolyposis colorectal carcinoma syndrome. Ceska Gynekol 1996;77:1836-1843.

15 Siah SP, Quinn DM, Bennett GD, et al. Microsatellite instability markers in breast cancer: a review and study showing MSI was not detected at 'BAT 25' and 'BAT 26' microsatellite markers in early-onset breast cancer. Breast Cancer Res Treat 2000;60:135-142.

16 Spagnoletti I, Pizzi C, Galietta A, et al. Loss of hMSH2 expression in primary breast cancer with p53 alterations. Oncol Rep 2004;11:845-851.

17 Walsh MD, Buchanan DD, Cummings MC, et al. Lynch syndrome-associated breast cancers: clinicopathologic characteristics of a case series from the Colon Cancer Family Registry. Clin Cancer Res 2010;16:2214-2224.

18 Shia J, Ellis NA, Paty PB, et al. Value of histopathology in predicting microsatellite instability in hereditary nonpolyposis colorectal cancer and sporadic colorectal cancer. Am J Surg Pathol 2003;27:1407-1417.

19 Wright CL, Stewart ID. Histopathology and mismatch repair status of 458 consecutive colorectal carcinomas. Am J Surg Pathol 2003;27:1393-1406.

20 Walsh MD, Cummings MC, Buchanan DD, et al. Molecular, pathologic, and clinical features of earlyonset endometrial cancer: identifying presumptive lynch syndrome patients. Clin Cancer Res 2008;14: 1692-1700.

21 van den Bos $M$, van den Hoven M, Jongejan E, et al. More differences between HNPCC-related and sporadic carcinomas from the endometrium as compared to the colon. Am J Surg Pathol 2004;28:706-711.

22 Parc YR, Halling KC, Burgart LJ, et al. Microsatellite instability and hMLH1/hMSH2 expression in young endometrial carcinoma patients: associations with family history and histopathology. Int J Cancer 2000;86:60-66.

23 Okudaira K, Kakar S, Cun L, et al. MUC2 gene promoter methylation in mucinous and non-mucinous colorectal cancer tissues. Int J Oncol 2010;36:765-775.

24 Melis M, Hernandez J, Siegel EM, et al. Gene expression profiling of colorectal mucinous adenocarcinomas. Dis Colon Rectum 2010;53:936-943.

25 Biemer-Hüttmann AE, Walsh MD, McGuckin MA, et al. Mucin core protein expression in colorectal cancers with high levels of microsatellite instability indicates a novel pathway of morphogenesis. Clin Cancer Res 2000;6:1909-1916.
26 Newcomb PA, Baron J, Cotterchio M, et al. Colon Cancer Family Registry: an international resource for studies of the genetic epidemiology of colon cancer. Cancer Epidemiol Biomarkers Prev 2007;16: 2331-2343.

27 Elston CW. The assessment of histological differentiation in breast cancer. ANZ J Surg 1984;54:11-15.

28 Lacroix-Triki M, Lambros MB, Geyer FC, et al. Absence of microsatellite instability in mucinous carcinomas of the breast. Int J Clin Exp Pathol 2010;4:22-31.

29 Ellis IO, Schnitt SJ, Sastre-Garau X, et al. Invasive breast carcinoma, In: Tavassoli FA, Devilee P(eds). World Health Organization Classification of Tumours. Pathology \& Genetics of Tumours of the Breast and Female Genital Organs. IARC Press: Lyon; 2003, pp 9-112.

30 Hanski C, Hofmeier M, Schmitt-Graff A, et al. Overexpression or ectopic expression of MUC2 is the common property of mucinous carcinomas of the colon, pancreas, breast, and ovary. J Pathol 1997;182:385-391.

31 Chu JS, Chang KJ. Mucin expression in mucinous carcinoma and other invasive carcinomas of the breast. Cancer Lett 1999;142:121-127.

32 Rakha EA, Boyce RW, Abd El-Rehim D, et al. Expression of mucins (MUC1, MUC2, MUC3, MUC4, MUC5AC and MUC6) and their prognostic significance in human breast cancer. Mod Pathol 2005;18:1295-1304.

33 Adsay NV, Merati K, Nassar H, et al. Pathogenesis of colloid (pure mucinous) carcinoma of exocrine organs: coupling of gel-forming mucin (MUC2) production with altered cell polarity and abnormal cell-stroma interaction may be the key factor in the morphogenesis and indolent behavior of colloid carcinoma in the breast and pancreas. Am J Surg Pathol 2003;27: 571-578.

34 Matsukita S, Nomoto M, Kitajima S, et al. Expression of mucins (MUC1, MUC2, MUC5AC and MUC6) in mucinous carcinoma of the breast: comparison with invasive ductal carcinoma. Histopathol 2003;42:26-36.

35 Walsh MD, McGuckin MA, Devine PL, et al. Expression of MUC2 epithelial mucin in breast carcinoma. J Clin Pathol 1993;46:922-925.

36 O’Connell FP, Wang HH, Odze RD. Utility of immunohistochemistry in distinguishing primary adenocarcinomas from metastatic breast carcinomas in the gastrointestinal tract. Arch Pathol Lab Med 2005;129: 338-347.

37 Ho SB, Niehans GA, Lyftogt C, et al. Heterogeneity of mucin gene expression in normal and neoplastic tissues. Cancer Res 1993;53:641-651.

38 Kato N, Endo Y, Tamura G, et al. Mucinous carcinoma of the breast: a multifaceted study with special reference to histogenesis and neuroendocrine differentiation. Pathol Int 1999;49:947-955.

39 Sóñora C, Mazal D, Berois N, et al. Immunohistochemical analysis of MUC5B apomucin expression in breast cancer and non-malignant breast tissues. J Histochem Cytochem 2006;54:289-299.

40 Berois N, Varangot M, Sóñora C, et al. Detection of bone marrow-disseminated breast cancer cells using an RT-PCR assay of MUC5B mRNA. Int J Cancer 2003;103:550-555.

41 Vgenopoulou S, Lazaris AC, Markopoulos C, et al. Immunohistochemical evaluation of immune response in invasive ductal breast cancer of nototherwise-specified type. The Breast 2003;12:172-178. 
42 de Bolós C, Guma M, Barranco C, et al. MUC6 expression in breast tissues and cultured cells: abnormal expression in tumors and regulation by steroid hormones. Int J Cancer 1998;77:193-199.

43 Andrianifahanana M, Moniaux N, Batra SK. Regulation of mucin expression: mechanistic aspects and implications for cancer and inflammatory diseases. Biochim Biophys Acta 2006;1765:189-222.

$44 \mathrm{Li}$ WQ, Kawakami K, Ruszkiewicz A, et al. BRAF mutations are associated with distinctive clinical, pathological and molecular features of colorectal cancer independently of microsatellite instability status. Mol Cancer 2006;5:2.

45 Haverty PM, Fridlyand J, Li L, et al. High-resolution genomic and expression analyses of copy number alterations in breast tumors. Genes Chromosomes Cancer 2008;47:530-542.

46 Yoshikawa A, Kuramoto S, Mimura T, et al. Peutzjeghers syndrome manifesting complete intussusception of the appendix and associated with a focal cancer of the duodenum and a cystadenocarcinoma of the pancreas-report of a case. Dis Colon Rectum 1998;41:517-521.

47 Bhargava R, Gerald WL, Li AR, et al. EGFR gene amplification in breast cancer: correlation with epidermal growth factor receptor mRNA and protein expression and HER-2 status and absence of EGFRactivating mutations. Mod Pathol 2005;18:1027-1033.

48 Koletsa T, Kotoula V, Karayannopoulou G, et al. EGFR expression and activation are common in HER2 positive and triple-negative breast tumours. Histol Histopathol 2010;25:1171-1179.
49 Vaughn CP, Zobell SD, Furtado LV, et al. Frequency of KRAS, BRAF, and NRAS mutations in colorectal cancer. Genes Chromosomes Cancer 2011;50:307-312.

50 Pinheiro M, Ahlquist T, Danielsen SA, et al. Colorectal carcinomas with microsatellite instability display a different pattern of target gene mutations according to large bowel site of origin. BMC Cancer 2010;10:587.

51 Mesquita P, Jonckheere N, Almeida R, et al. Human MUC2 mucin gene is transcriptionally regulated by $\mathrm{Cdx}$ homeodomain proteins in gastrointestinal carcinoma cell lines. J Biol Chem 2003;278:51549-51556.

52 Almeida R, Silva E, Santos-Silva F, et al. Expression of intestine-specific transcription factors, CDX1 and CDX2, in intestinal metaplasia and gastric carcinomas. J Pathol 2003;199:36-40.

53 Hahn HP, Blount PL, Ayub K, et al. Intestinal differentiation in metaplastic, nongoblet columnar epithelium in the esophagus. Am J Surg Pathol 2009;33:1006-1015.

54 Werling RW, Yaziji H, Bacchi CE, et al. CDX2,a highly sensitive and specific marker of adenocarcinomas of intestinal origin: an immunohistochemical survey of 476 primary and metastatic carcinomas. Am J Surg Pathol 2003;27:303-310.

55 Pereira MB, Dias AJ, Reis CA, et al. Immunohistochemical study of the expression of MUC5AC and MUC6 in breast carcinomas and adjacent breast tissues. J Clin Pathol 2001;54:210-213.

56 Matsuda M, Sentani K, Noguchi T, et al. Immunohistochemical analysis of colorectal cancer with gastric phenotype: claudin-18 is associated with poor prognosis. Pathol Int 2010;60:673-680.

Supplementary Information accompanies the paper on Modern Pathology website (http://www.nature.com/ modpathol) 